\title{
The Role of Family Disintegration in Piracy of Electronic Games "A Field Study"
}

\author{
Heba Atef El-Sayed Mahmoud Awad
}

Lecturer at Sociology Department [Faculty of Arts- Damietta University], Egypt

\begin{abstract}
Purpose: Recognizing the technological effects of family disintegration.
Method: Human field: a sample of the dangerous electronic games players, including "4" players who are still alive, and "5" players who committed suicide. Methods and Tools: The Case study method, Ethnographic method, Descriptive approach, and Interview. The research type is Analytic, and the theoretical framework is Postmodernism Theory.

Originality: The researcher tries to provide a comprehensive view of how electronic games piracy on their players and pushes them to suicide, in the presence of the family disintegration element.

Findings: family disintegration was the main reason for children's addiction to electronic games. Thus, electronic games were like escaping from reality and living in imagination, and spending free time. Also, electronic games were a means that absorbed the negative charge and feelings of anger among the children instead of the family. There are many types of piracy on players: (programming for the mind, charging with negative thoughts, threatening to kill parents, an emotional challenge to the teenager, blackmail and intimidation, or with talismans).

Conclusion: a person can control another, to the extent that this other person allows this person to control him. Do not allow a game administrator to control you, activate Cybersecurity.
\end{abstract}

Keywords: Electronic games, family disintegration, Piracy.

THE THEORETICAL AND METHODOLOGICAL FRAMEWORK FOR RESEARCH

\section{FIRST: AN INTRODUCTION}

The knowledge society is Including many forms of family disintegration of all kinds, whether it is a physical family disintegration (that is: the family lives far from each other, as they aren't at the same house), or a moral family disintegration (that is: the family lives with each other in one home, but each has his own isolated life).

In this deterioration in family conditions, electronic games find a fertile environment that allows them to sneak into the lives of children and control them.

\section{SECOND: THE RESEARCH PROBLEM}

The current "information Society" contains a huge wave of the electronic invasion of children's minds, also the disintegrated family atmosphere in recent times, allows electronic games to dominate most adolescent Sons. As children find in those games an enjoyable way to spend their time and empty the negative charge resulting from family disintegration.

\section{THIRD: THE IMPORTANCE OF RESEARCH}

\section{Theoretical Importance}

The research seeks to present a scientific treatment on the topic: The role of family disintegration in the

*Address correspondence to this author at the Sociology Department [Faculty of Arts- Damietta University], Damietta University, New Damietta, Egypt; Fax: (+20)572370204; E-mail: hebaatef@du.edu.eg piracy of electronic games "a field study". As the researcher focuses on studying dangerous games that have appeared recently, to try to add recent results in the sociology field.

\section{Field Importance}

The researcher tries to provide a comprehensive view of how electronic games piracy on their players and pushes them to suicide, in the presence of the family disintegration element.

\section{FOURTH: RESEARCH OBJECTIVES}

1. Recognizing the technological effects of family disintegration.

2. Study the phenomenon of electronic games piracy.

3. Finding solutions and proposals to limit the control of electronic games.

\section{FIFTH: THE STUDY QUESTIONS}

Q1: What are the technological effects of family disintegration?

Q2: How does the piracy of electronic games on children?

Q3: What are the solutions to limit the control of electronic games? 
SIXTH: THE METHODOLOGICAL FRAMEWORK AND THE TOOLS USED IN THE RESEARCH

\section{Research type}

(Analytic). The researcher analyzed the lives of the cases and tried to link the common elements between them.

\section{Methods and Tools}

- $\quad$ The Case study method: The researcher tried to reach the largest available number of victims of dangerous electronic games through: (students of the first teams in some colleges and institutes _ some school students: primary, preparatory and secondary _ some journalists). She studied their lives extensively and reached the largest and most accurate information possible about them, their families, and their social level.

- $\quad$ Ethnographic method: The researcher observed and studied the dialogues of members of the dangerous electronic games pages on Facebook.

- Descriptive approach: where the description of opinions of community members and the reactions of public opinion in various social media towards dangerous electronic games in various countries. This is in addition to a description of the playing way.

- Interview tool:

Online Interview: where directing the case study guide questions to (some of the players' teachers, and also some of their neighbors) using Facebook Messenger, WhatsApp, and Instagram. This is in addition to making many phone calls with family members of the victims, due to the sensitivity of the topic of their son's suicide, so it was difficult to meet them face-toface.

Paper interview: through an interview with (acquaintances and neighbors of the sample members face-to-face, and directing the questions of the case study form guide to them).

In-depth interview: With the players who are still alive, as they managed to escape from the game and did not complete the levels.

\section{Research areas:}

- Geographical area: The field procedures for the research were carried out in two directions. The first of them is: (Cairo _ Talkha _ Damietta _ Dakahlia _ Tanta _ Mahalla al-Kubra) in Egypt, and the second: on social networks, and also some news sites.

- $\quad$ Time range: (Almost three years), from April 2018 to February 2021.

- Human field: a sample of the dangerous electronic games players "that the researcher was able to reach". Including "4" players who are still alive. And " 5 " players who committed suicide, and here the case study guide was applied with the help of families and acquaintances of suicide.

\section{SEVENTH: THEORETICAL FRAMEWORK}

\section{Postmodernism Theory}

It would be wrong to rely on postmodernism and post-structuralism which directed the arrows of criticism forward to the modern, without understanding the modern thought. Modernism can be possible to evaluate from the beginning of the Enlightenment in the 18th century until the first half of the 20th century, where the basic concepts for this period were: rationality _ sovereignty_ logic _ scientific _ universal facts _ systematic thought _ positivism. Thus, modernism is based on the principles of the Enlightenment. Where reason and science are seen as means for progress; The basic argument is objectivity and universal knowledge that can be reached through reason and experience. Thus, postmodernism is an extension of modernism. It can be seen from a historical perspective that the failure of modernism to reach perfection led to the birth of postmodernism (Mehmet Emin Erendor, Mehmet Fatih Oztarsu: 2020).

Modernism has lost its validity in Western culture because the premise of historical knowledge has become untenable. The theory of the Enlightenment that depends on the scientific community with its experimental objective culture, which is represented in individualism and social particularities (which study subjects such as class_ gender _ nationality) has ended, and the postmodernism that produced thought that is concerned only with the truth appeared (Seidman 1998). 
(Miller 1997) assumed that in our modern capitalist material world, there appeared an orientation towards things instead of persons, so things became symbolizing people, as they made us merely a "lifestyle" that works according to the meanings made for us within the capitalist society (Clarke 2003).

\section{Employment of Postmodern Theory in the Service of Current Research}

The technological spread in the current century made it very easy for children to access many dangerous electronic games and download them to their devices. In addition to the existence of the family disintegration factor, this led to the absence of parents' follow-up of their children, so many teenagers and the youth fell into the trap of electronic games, and they became easy prey for them.

These players were coded. So that they must carry out the orders of games that were made for them within a postmodern society, and so that the individuals were transformed into a "physical pattern" as Miller assumed.

\section{EIGHTH: PREVIOUS STUDIES}

\section{Axis of Family Disintegration}

Factors Related to the Disintegration of Family Relations and their Relationship with Psychological Adjustment and Feeling of Loneliness among Youth - 2016

The research (Kandil, et al., 2016) aims that: identify the causes (social, technological, etc.) related to family disintegration. A questionnaire was applied. The research found that the nature of interaction in the technological society leads to weak social relations, which reduces the role of the family. The research recommends that: attention to family relationships reduce loneliness.

\section{Axis of electronic games piracy}

\section{Youth Engulfing Blue Whale: Monomania or Social Construct? - 2019}

The importance of the study (Chakraborty 2019) in dealing with the suicides that have spread in recent times due to the "blue whale challenge". The aim of this paper: discover the social and psychological factors which lead to that self-annihilation. The paper is based on Durkheim's theory. And he concluded that suicide is a result of "mental deliria, melancholy, obsessive, or alienation", which is an indication of a crisis in society as a result of continued rapid change.

Media, Violence and the Culture of Victimization: A Sociological Analysis of the Socio-Cultural and Psychological Impacts of Media on Youth - 2015

The study (Naz, et al., 2015) confirms that exposure to violence in the media, such as television and video games, represents a great danger to the personality of children. It contributes to their aggressive behavior, violence as normal, nightmares, fear of harm. The research was conducted on a random sample of (100) secondary students in Pakistan. The study reflected the positive role of the media, as well as the negative role in creating tension, fear, anxiety, frustration, aggression, and a culture of victimization. The research recommended an initiative to overcome the consequences of the rapid spread of the media, represented in workable policies.

\section{Longitudinal Effects of Violent Video Games on Aggression in Japan and the United States - 2008}

The importance of the study (Anderson, et al., 2008) is due to the youth around the world spending many hours a week playing violent video games. The study was based on the experimental method, and it was tested: Whether the frequent exposure to violent video games increases physical assault in all global cultures of violence or not? The experiment was conducted on three independent samples, differing in gender and age "12: 18" years. The study found that exposure to violent video games at the beginning of the school year is a risk factor, as it would predict physical aggression later.

The relationship of the Current Research to Previous Studies

1. This research agreed with previous studies that the increasing use of electronic games by children, due to personal, social, and technological factors.

2. This research disagreed with previous studies in the application of the "case study" method.

3. This research benefited from previous studies in confirming the hypothesis of the effect of electronic games on their users.

4. This research added some new things, as monitoring the relationship between family disintegration and the effect of dangerous electronic games on children. 


\section{NINTH: FAMILY DISINTEGRATION}

It is the collapse of the family union, and the failure of one or more individuals to perform the role assigned to him within the family. The forms of family disintegration are many and varied, including divorce, desertion, separation, imprisonment, illness, and death (Sharif, 2008), father travel to work, and the mother's exhaustion of bearing the responsibility of the family alone. There is a modern image, which is the presence all family members are together, but each of them is busy with their private life due to the modern technological life.

As for the procedural concept adopted by the research, it is the lack of (social communication) in the family environment, which pushes the children to search for an alternative, which is (technological communication), this is because we are in a knowledge society.

\section{TENTH: PIRACY OF ELECTRONIC GAMES}

\section{Definition of Electronic Games}

They are every game that is played on an electronic device, such as a mobile phone.

\section{Reasons for its Addiction}

It provides an attractive environment for various age groups, due to its diversity between games: (battles, thinking, racing, science fiction, providing an adventurous spirit, including individual and team games).

\section{Its Problems}

intellectual terrorism against the player's personality to fulfill the orders of the game directors (Hassan 2020), isolation, lack of sleep, imitation of the violent personality of the game hero, and learning Tricks of committing crimes.

\section{Its Advantages}

Activating the player's blood circulation through high-tech games where it asks him to make virtual movements with his body that show their effect on the screen instead of using the device control tool (ElRazzak and Hayat 2018), using the simulation element to teach some skills such as self-defense, Promptitude, the ability to do several tasks at the same time, planning, and patience for the goal.
In sum, a person is social by nature. And if the relationship between him and his family members weakens, he will go directly to an alternative that compensates him for this defect (Mohammed 2016), this alternative that children find in their electronic games. The concept of "piracy" appears here, which is that: These electronic games dominate the player and impose control on him, as this is the terrorism of a new kind that penetrates minds.

\section{ELEVENTH: THE IMPACT OF FAMILY DISINTE- GRATION ON PLAYING ELECTRONIC GAMES}

1. The isolation of children with their electronic games: in their rooms at home, or in Internet cafes.

2. A large number of problems between children and one of the parents who is always advised to pay attention to studies and reduce electronic games, "as one of the main problems of family disintegration is that one of the parents places full responsibility on the other."

3. Children get to know new individuals through collective electronic games that require forming groups to fight other groups, as an attempt to compensate for the deficiency within the family atmosphere.

4. Children are more interested in electronic games than in family life that son learns to hack games that require payment to play, and plays them without paying anything. He learns violence and is no longer averse to trying death games.

5. The admin of dangerous games takes advantage of the absence of parents and programs the player's mind on violent pornography, so he becomes accustomed to terrorizing the other, and even hurting himself.

\section{APPLICATION FRAMEWORK FOR RESEARCH}

\section{FIRST: AN INTRODUCTION}

The researcher polled 376 people about: (the most dangerous electronic game from their point of view, and what games they play or know). To reach this, the researcher used (interviews, telephone conversations, text messaging, Facebook, WhatsApp, Twitter, Instagram).

The researcher found that: The games that caused an uproar in recent times were: Blue Whale, Mariam. 
This is because of their victims who committed suicide around the world. Accordingly, the researcher conducted in-depth interviews and applied a case study guide with the players or one of their relatives if the player committed suicide.

This is in addition to some other games that the researcher will mention in the search results.

\section{SECOND: DETERMINING THE TYPE OF SAMPLE AND THE METHOD OF TESTING IT}

The type of the research sample was determined as (intentional) of serious electronic game players. The case study guide was applied to this sample.

\section{THIRD: SOME CASE STUDY FORMS}

\section{Case (1)}

\section{First: The Basic Data}

Player Name: (A. A.) \& Gender: Female

1. Age of player: (18) years.

2. Education of the player: First year in the university.

3. Education of the player's father: university.

4. Education of the player's mother: university.

5. Player's father's career: employee + self-works.

6. Player's mother's career: a housewife.

7. Family income: High.

8. Residence: New Damietta City _ Egypt.

9. The name of the electronic game: Blue Whale. She plays it in her room on her phone.

\section{Second: Family Disintegration}

10. Family life: The family lives in one house, but the father's working conditions force him to travel most of the time. The player is the youngest and she has (4) brothers, of whom (3) are married. The player's relationship with her family members is cordial, but there is a side of disagreements and disputes due to the player's constant use of technology.

11. How a player spends her day: Waking up early to go to college, attending lectures, and then maybe going out with her friends. Coming home and having lunch with her family, reviewing her lectures, and going to the Internet.

\section{Third: piracy of electronic games}

12. The player's character before and after playing the blue whale game:

- Before: a girl who seemed very calm, and was learning computer programs and their general use. She entered the hacker field, and she had a great passion for discovering dangerous new electronic games, so she heard about Mariam and the Blue Whale. She began to try the game of Mariam and finished the last level, and she said that the game is just entertainment and not how dangerous people talk about. Which made her motivation to play the Blue Whale game also, thinking that it is easy like Mariam.

She was a person who liked to get to know foreign friends through the Internet and could chat with them in their foreign language. Here, was the beginning of her entry into the blue whale two years before entering college, where the game was at the beginning of her appearance in the world in 2016; Through a foreign friend (Gabriel T.), who was playing the blue whale game and then entered the neuropsychiatric hospital because of the game, and when Gabriel told what happened to her, she raised the player's spirit of challenge, as she did not believe what happened and was stronger than any game.

She downloaded the game on her recent iPhone because it didn't accept the download on the old Nokia. As soon as it was installed, the game started working on the hacker (all the videos, pictures, and personal data of the player were stolen from the mobile phone and the player's Internet pages). And she started playing. The first question was: What do you like and what are you afraid of? Your life is beautiful and do you accept it or not? Whether social, economic, or other life? Where is your social life? Who are you close to? Who do you live with? The player answered. Then, entered the first stage, which was a drawing of a whale on a piece of paper, shooting a picture to it. Then, send it to the admin of the game.

- After: Many problems occurred in her life that made her cut off from the surrounding world for a long time, where; Blue Whale Admin asked the player to transfer talismans and logarithms from the game onto the paper on which she drew the 
whale. The player says: I didn't think I was doing this purely, but I was feeling that there was a thing that would let me do the words. And they asked me not to inform my family of anything, and I have transferred the drawing of the blue whale to my leg on the thigh using a cutter. The researcher asked the player: Did you feel pain? She said something simple like just scribbling.

The player mentioned that the background to the game is a blue whale. The game has specific music, meaning that if a message from the game or any command arrived, you hear the sound of the game's music and see the message directly on the screen without opening it or anything. If the player did not wake up at the specified time, the game would make its music and open the mobile phone even if it was switched off. Among the commands: Waking up at night "2: 4 AM" and watching videos and listening to songs sent by the game, which are incomprehensible words translated into Arabic for the player. Although they did not ask the player about her language, she believes that the game knew her language through its location using JPS mobile. The songs cause depression for those who hear them and a very bad mood, and the movies are horror movies about murder. Also, there are some commands like injuring any place on the player's body that has many veins to bleed a lot of blood. And standing on: the wall of the balcony of the house, and a bridge fence underneath the water, and sending pictures to the admin.

The player has reached a level (20). Admin asked her to go to the cemetery at 2 am, and she must walk among the cemeteries for a full hour. And shoot a picture of the scene there and send it to the admin. The difficulty was, how does she get out of the house at this time? She did not implement for several nights, and every night the admin sends her messages urging her to come down, but she cannot. Until a night came when the father was outside the house, the mother and the brother were asleep, and the player came to a threatening message: If you do not go to the graves, we will kill your family. The girl was frightened and prepared to go down, and indeed, she went down the stairs. At the door of the building below, she met the father, who was very surprised when he saw her in the outfits clothes. He said to her, Are you out? She said no, he told her why do you wear outdoor clothes? She told him it was normal and her face she knew was confused, which aroused the father's suspicion. In those moments, a message came on the girl's mobile, and the girl says that her father pulled the phone from her to see the message and he saw the game in front of him, written in it: Did you go or not? If you don't go down today, all of you will be killed. Here, the father asked her, "What is this?" Then the girl collapsed and narrated what happened to her, and that she was afraid of being killed.

When her father saw the message, threw her mobile phone on the ground and broke his screen. He took his daughter to the house and told the family what had happened. From here, they withdrew the mobile from her and prevented her from communicating with anyone. And they put her under extreme observation to the extent that her mother used to go to the bathroom with her because they were afraid to do something in herself. The girl told me that one time her mother saw a drawing of a whale on her leg and asked her what is this? She told her because of the game. The researcher asked the player: How much time has passed since the subject of the drawing? She told me two months, I said: you told me that you sensed with just a slight scratch as you said? Here, the researcher felt that the player was embarrassed that I thought she had lied to me. And she assured me that she only felt a simple scribble, so she continued. She naturally does not like blood. (Note) The broken mobile screen was fixed. And they downloaded the software update, but the game was not cleared from the device, so they sold it. And they changed their place of residence completely.

\section{Case (2)}

\section{First: The Basic Data}

Player Name: (M.) \& Gender: Male

1. Age of player: (12) years.

2. Education of the player: $6^{\text {th }}$ grade of primary school.

3. Player's father's career: traveler.

4. Player's mother's profession: primary teacher.

5. Family income: High.

6. Residence: Attended "Damietta City _ Egypt".

7. The name of the electronic game: Blue Whale.

\section{Second: Family disintegration}

8. Family life: The mother lives with her three children, the player is the second son, and he has an older brother and a younger brother. 
9. The relationship between the "electronic games player" and members of his family:

- $\quad$ Mother: After the mother knew that her son was playing the Blue Whale game, she prevented him from using the tablet, which he played the game on it. And downloaded the software for the device, but the game was not deleted. And she took his mobile from him. The mother usually neglects this son, and she admits that; in the beginning, the older son was taking all her time and the little son was autistic.

The son blames his mother and father for raising their voices often at home. And he asks: Are we going to be raised loudly? Hence, he is very hostile to his mother. He says to her: (I am nothing for you, you want me to succeed so that they say your son succeeded).

The mother was completely ready to meet the researcher to cooperate with her in solving the son's problem. Rather, it was the mother herself who was looking for someone to solve her son's problem, but then the mother refused to meet the researcher. And she was evading in various ways, so the researcher got all the information from two teachers in the student's school.

- Little brother: The player is angry with the presence of this younger brother and his health conditions.

\section{Third: Piracy of Electronic Games}

10. The player's character before and after playing the blue whale game:

- Before: intelligent, and his scientific level is very excellent. He likes to try things to learn by himself. He has a great interest in human development courses until the financial condition of his family deteriorated, he shied away from taking those courses. He has friends, but only from characters who are weaker than him. He likes to be the leader, and he doesn't like anyone to oppose him.

- After: The boy has been playing the game for about three weeks. Then, he stopped it because he was very afraid when the game asked him to draw the whale on his hand with a sharp tool. Then, photograph it and send it to the admin of the game, to be loyal to this leader. After that, the boy said, "A person appeared to him in front of his real home and threatened to kill him if he did not continue in the game. The student's teacher analyzed the arrival of this person who appeared in front of the house through the JPS present in modern mobiles). The game admin attempts to keep the player to complete the game by sending him threats via his friends.

The student loves his teacher very much and is attached to her. Therefore, he told her that: He began to see things that were not good. And he became sitting a lot in the bathroom, and he did not feel the time except after he left and looked at the hour. "Once, he entered the bathroom at $8 \mathrm{pm}$ and only came out at $2 \mathrm{am} "$. He admires his shape and likes to look in the mirror.

Then his passion went to reading magic books. And he got to know a person like him who is frightened completes the levels of the game, and this person is the one who gives him the magic books "and is aware of the mother". The student's teacher warned the parents of the second boy who brought books of magic but was indifferent. The worst thing is that when he cannot access some books of magic, he downloads them on the internet for a sum of money. He has reached the stage of being able to decipher the algorithms of magic, and he cannot do that unless he read books about black magic. He is a child who loves fantasy and myths. And his teacher had taken from him a promise not to read those books again, but he did not abide by this promise.

Unfortunately, despite the student's love for his teacher, recently he has started to distance himself from her. When she tried to keep him away from the field of magic, he replies, "I read books, what happened to me, did something bad happen to me?" He stays away from studying. His mother became afraid of him as she feels that he is not normal, especially from the shape of his eye, which is dominated by the blood-red color.

11. Solutions to reduce the dominance of electronic games over children:

A seminar about the danger of the game of the blue whale has already been organized at the institute where the student learns. The seminar included students and their parents, but parents blame modern technology, whether it is the net or mobile phones. These mobiles that parents give to their children as a gift for their academic success. Then, they do not care 
about these children who are then busy in the world of technology. The teacher notes that during that seminar, one of the mothers said: her son started looking for sharp tools in the kitchen such as: "zucchini peeler, potato slicer, small knives" and he sits in places alone.

The teacher notes that there have been many cases of playing a blue whale, which hurts her greatly because she cannot do anything. As the number of the class is (40) students, of whom about (15) changed due to the blue whale game.

\section{Case (3)}

\section{First: The Basic Data}

Player Name: (S. A.) \& Gender: Male

1. Age of player: (12) years.

2. Education of the player: $6^{\text {th }}$ grade of primary school.

3. Education of the player's father: a diploma.

4. Education of the player's mother: a diploma.

5. Player's father's career: tourist bakery owner.

6. Player's mother's profession: housewife.

7. Family income: average.

8. Residence: Rural "Belqas - Dakahlia" Egypt.

9. The name of the electronic game: Blue Whale, he plays it inside his room.

\section{Second: Family Disintegration}

10. Family life: The family does not live in one house but in separate places. The mother, the player, the young son, and the grandmother are in a house. And the father is another.

\section{Third: Piracy of Electronic Games}

11. The player's character before and after playing the blue whale game:

- Before: a very social person, who knows many people, and seeks to get to know new people. He wakes up at seven in the morning to go to school, then comes home to spend time with his family, especially his little brother, to play with him. When the father comes to the house, he would sit with him as well, talk to him about what happened in the previous period. Then, go out with his friends. He used to go to the field to pursue agricultural work. He had hobbies such as painting and football.

- $\quad$ After: (The player's father narrated these details after the player's suicide). He said that the game negatively affected the son as if it were causing him hypnosis or magic, making him lose consciousness. He was sitting alone as the game ordered him to do. He turned into a loner and an introvert, he no longer communicated with his family, did not go the field, and did not practice his hobbies. Until he was found hanged in his room. He hanged himself with a rope tied to a ceiling fan. There was a chair on the ground that the player used to climb onto it and wrapped the rope around his neck and then kicked the chair with his feet. He suffocated and died.

After death, the player's body had abnormal marks. As his back was half blue and the other half red.

Case (4)

First: The Basic Data

Player Name: (M. M. A.) \& Gender: Male

1. Age of player: (18) years.

2. Education of the player: third-grade secondary school.

3. Education of the player's father: a diploma.

4. Education of the player's mother: a diploma.

5. Player's father's career: Carpenter.

6. Player's mother's profession: housewife.

7. Family income: average.

8. Residence: Urban "Belqas center - Dakahlia" Egypt.

9. The name of the electronic game: Blue Whale, he plays it inside his room at night.

\section{Second: Family Disintegration}

10. Family life: they live in one house. The player is the only son of the family, but they do not sit together.

\section{Third: Piracy of Electronic Games}

11. The player's character before and after playing the blue whale game: 
- $\quad$ Before: A friend of the player said that he spent most of his time studying, and little time with family and friends. Then, he enters his room to spend his duties. He heard about the blue whale game and was not convinced of its seriousness. He decided to play it out of passion, selfaffirmation, challenge, and escape from the psychological pressures that he lives in because of the family throughout his studies.

- After: complete isolation from the family, fear, and introversion. The family thought that the reason was the pressure to study until they found the player hanged in his room. It was suspended from a wire at the top of the room's ceiling.

The player left a message for his father and mother; $\mathrm{He}$ admitted that he was a disobedient son and that he was far from God. He did not expect that he would one day accept a suicide move, but he would commit suicide for fear of his family being killed. He entered the Blue Whale game due to the pressure of the father and mother to study, which destroyed his psyche. He knows that his family wanted him to succeed, but he did not, and he asked them to pray for him.

\section{Case (5)}

\section{First: The Basic Data}

Player Name: (--) \& Gender: Male

1. Age of player: (14) years.

2. Education of the player: second grade preparatory.

3. Education of the player's father: a diploma.

4. Education of the player's mother: a diploma.

5. Player's father's profession: freelance business.

6. Player's mother's profession: housewife.

7. Family income: average.

8. Residence: Cairo - Egypt

9. The name of the electronic game: Blue Whale, he plays it inside his room on his laptop.

\section{Second: Family Disintegration}

10. Family life: a family lives in one house. Their cultural level is low. There is severe child neglect and family disintegration.

\section{Third: Piracy of Electronic Games}

11. The player's character before and after playing the blue whale game:

- Before: a normal teenager, but he might have some personality disorder.

- $\quad$ After: The player's family opened his room and found him hanging himself. The laptop was open to the Blue Whale game. It was in 2018 before that game became popular.

Case (6)

First: The Basic Data

Player Name: (Khaled M.T.) \& Gender: Male

1. Age of player: (12) years

2. Education of the player: Sixth grade of primary school.

3. Family income: average.

4. Residence: The city of "Tanta" - Egypt.

5. The name of the electronic game: Blue Whale, he plays it on the mobile phone.

\section{Second: Family Disintegration}

6. Family life: The family lives in one house, but there are some disturbances.

\section{Third: Piracy of Electronic Games}

7. The player's character before and after playing the blue whale game:

- Before: normal kid

- After: The child was taken to hospital with phosphorous poisoning, due to ingesting a toxic substance. The doctor said that the child took the lethal preservative pill, which is a very toxic pill. Mostly gastric lavage is done for those who take it, but survival is seldom. The doctor added, "I do not believe myself, and I did not honestly talk about the blue whale game except when I saw that emergency myself. I see deaths a lot, but the first time I get affected. I asked the child before he died, why did you take the lethal pill? The child pointed to his right arm, which had a drawing of the blue whale. The doctor filed a report of the incident to the police station about what happened. 


\section{Case (7)}

\section{First: The Basic Data}

Player Name: (M. R.) \& Gender: Male

1. Age of player: (21) years old.

2. Education of the player: First Year Institute.

3. Education of the player's father: a diploma.

4. Education of the player's mother: institute.

5. Player's father's profession: Carpenter.

6. Player's mother's profession: housewife.

7. Family income: average.

8. Residence: Rural "Kafr El Tawila - Dakahlia" Egypt.

9. The name of the electronic game: Maryam game, he plays it on his phone in his room.

\section{Second: Family Disintegration}

10.Family life: The family lives in one house, but the player is isolated from his family members.

\section{Third: Piracy of Electronic Games}

11. The player's character before and after playing the Mariam game:

- $\quad$ Before: he used to go to his studies. He comes home to rest and satisfy some of his personal needs. He goes to the gym to do some activities. He was brave and strong.

- After: he was inclined to introversion and loneliness. He feels afraid of everything that approaches him. Then, he began to feel a tingling sensation in his head. The player told his family that he felt a headache that he was unable to handle. In addition, there is something more in his brain moving inside his head. His parents took him to neurologists, who conducted comprehensive examinations for him, which showed that he was in good condition, and advised them to go to a psychiatrist. Indeed, the player started going to the psychiatrist but did not tell him that he was playing Maryam.

Until one day, the player went to perform the noon prayer in the mosque. When he returned, he told his family that he was suffering from fatigue due to lack of sleep and then entered his room. After two hours had passed, his mother went to wake him up for lunch. As she was surprised that her son was tied to his neck by a rope hanging from the ceiling of the room, and he had died. The parents did not know that their son was playing Maryam's game until after his death when his brothers found the game's application on his mobile phone.

Case (8)

First: The Basic Data

Player Name: (Mona A.) \& Gender: Female

1. Age of player: (20) years.

2. Education of the player: Third Year University.

3. Education of the player's father: neither read nor write.

4. Education of the player's mother: a diploma.

5. The player's father's profession: Carpenter, "migrant to work".

6. Player's mother's profession: housewife.

7. Family income: average.

8. Residence: Urban - Egypt.

9. The name of the electronic game: Maryam game, she plays it on his phone.

\section{Second: Family Disintegration}

10.Family life: the family lives together in one house, except for the father.

11.The relationship between "electronic game player" and her family: the player always prefers to sit alone.

\section{Third: Piracy of Electronic Games}

12. The player's character before and after playing the Mariam game:

- $\quad$ Before: She was a normal personality. She was characterized by being active, waking up early, exercising, and helping her family. She has friends and spends the day off with them. Also, interested in studying. The family had a basic daily habit of talking to their father over the internet. The player was sharing with them, but 
she had secrets with her father, not with her mother. The player loved very much to discover new electronic games with the aim of adventure until curiosity took her to try Maryam's game.

- $\quad$ After: The player has neglected its studies and its relationship with her father and girlfriends. The player became terrified and not reassuring, too crusher. Do not sit anywhere alone.

The player tried to commit suicide more than once: she ingested toxic substances, tried to throw herself from the house, severed her hand. This is because she was unable to sleep even for only five minutes. This is because of an idea controlling her mind: that Maryam is here and she will kill her if the player does not kill herself.

Thus, the game destroyed that girl's life and caused her severe psychological tension, until she entered a (psychiatric hospital) in which she spent (6 months) until she was treated.

\section{Case (9)}

\section{First: The Basic Data}

Player Name: (A. G.) \& Gender: Male

1. Age of player: (22) years.

2. Education of the player: Fourth Year University.

3. Education of the player's father: a university graduate.

4. Education of the player's mother: a university graduate.

5. The player's father's profession: civil engineer.

6. Player's mother's profession: teacher.

7. Family income: high.

8. Residence: Rural area "Manzala" - Egypt.

9. The name of the electronic game: Maryam game, which he plays at home on his phone.

\section{Second: Family Disintegration}

10. Family life: The family lives in one house, but they communicate in a very limited way because everyone is preoccupied with his personal affairs.

\section{Third: Piracy of Electronic Games}

11. The player's character before and after playing the Mariam game:

- $\quad$ Before: He was a normal, organized person. He went to his university regularly. He didn't have any fears. He was not short of anything.

- After: He no longer goes to his university regularly. He became nervous all the time, anxious and scared. He sits alone in his room for large times, and even refrains from talking with his family for long periods.

\section{FOURTH: THE MOST IMPORTANT FINDINGS AND MAIN CONCLUSIONS OF THE RESEARCH}

\section{Results Related to Basic Data for Players}

The case study guide was applied to a sample of (9) cases of players: Blue Whale and Maryam.

All Blue Whale players are from: (Adolescent), and they are the ones targeted by this game. As it is based on the principle of provoking the emotional side of the teenager: (I am old, so I can experience everything new, I bear the pain, and I am ready for adventure).

The category of adolescents is physiologically mature and not fully mature psychologically or emotionally. Thus, adolescents become easy prey for such destructive games. It should be noted that the players have a high level of intelligence and electronic skill. This is because this game is only available on certain websites, and not everyone has access to its original version.

As for the game of Mariam, it is played by young people. The researcher notes that there is another target group of another type of games, they are (the category of children), as these games depend on the naivety and innocence of children at a young age, such as (fairy game).

Player environments varied between (cities and countryside), as games now penetrate all developed and backward societies alike.

\section{Results Related to Family Disintegration}

The research showed that family disintegration was the main reason for children's addiction to electronic games. The most common form of it was that family members live with each other in one house, but everyone is isolated on his own. In addition to the 
emergence of another picture where the father is traveling to bring money, and the mother is responsible for living with the children.

Mothers of players were on opposite sides. Meaning: Some of them take great care of themselves and neglect their children, and some of them are strict in dealing with their children very much. Certainly, in both cases, it is a severe mistake in the right of children.

All players have family problems, such as hate family and home, strained relationships with family members. In addition to the fact that they are almost completely isolated from their families after the electronic games dominate them, they also neglect their studies.

Thus, electronic games were like escaping from reality and living in imagination, and spending free time. Also, electronic games were a means that absorbed the negative charge and feelings of anger among the children instead of the family (even one of the players said that she was talking to the toy in the game because she did not find anyone from her family to listen to her).

\section{Results Related to Electronic Game Piracy}

- There are many types of piracy on players: (programming for the mind, charging with negative thoughts, threatening to kill parents, an emotional challenge to the teenager, blackmail and intimidation, or with talismans).

- The researcher focused on (the blue whale game). It is a modern electronic game, which appeared among teenagers at the age of (12: 18) years. It is a game that is not accessible to everyone on all sites, but it must be searched well because it is on a few sites. The player downloads it, and he installs it.

The game begins in its activity where it hacks a teenager's device with its social media pages, videos, pictures, and personal data. It starts by gathering information about him, his family, and all of his relationships. The player cannot delete it after that even if he has downloaded software for his device. The game sends questions to the player to measure his ability to obey and know his level of self-confidence. This is because the game only accepts a teenager (obedient - desperate or has some depression and some problems).
The game displays the gameplay levels "consisting of fifty levels to be completed in fifty days". The levels differ according to the individual "player, leader". A player does not cross a level unless he has passed the level before it. A player does not pass more than one level per day. Each level is a command, sent by the leader and executed by the player. To prove the validity of the execution, the player filmed his action to the command. Then, he sends the pictures or video to the game admin, who in turn sends the next command to the player. And so on until the fifty level.

The commands in the game vary, including: Waking up from sleep at strange times to receive the new command from the leader. Watching horror movies. Cutting a toe. Hearing certain voices sent by the leader and music leads to depression. Writing certain phrases on Facebook such as I am a blue whale, the weather is beautiful today, or my friends, I invite you to the blue whale game. Photographing the family while they are sleeping and photographing the house. Walking on a fence in the home. Going out to the cemetery at night. Hurting parents or stabbing them with a knife. Drawing a whale with a sharp object on any part of the player's body. Commit suicide by hanging, or eating Toxic substances, or jumping from a high place, often the roof of the house.

If the player objects to any order and does not implement it, the game admin threatens him with death, or with videos that the player sent to the admin. Levels range from easiest to hardest. At the beginning of the levels, communication between the leader and the player is via text messages. After that, in the higher levels, communication takes place via video calls, where the game leader is shown wearing a blue whale mask for the teenager.

From the analysis of the cases: it was found that they were controlled using incantations and logarithms. As was the case with the player (A. A.), who used the drip to engrave a blue whale on her leg, and she did not feel anything, but a simple scribble. Also, the case (M) that everyone felt transformed into a human they

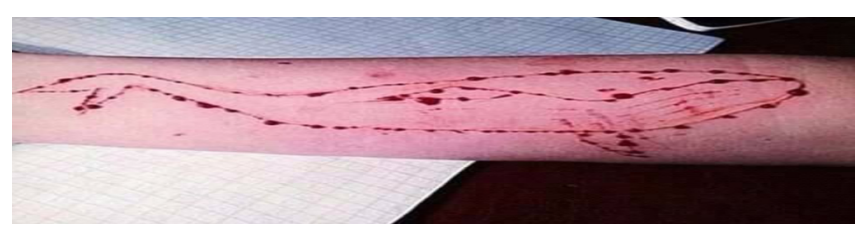

A picture shared by social media of an arm engraved on a whale 
feared. And cases that committed suicide and found in their rooms: papers written in which things are not understood.

- As for (Mariam's Game): it is a fictional story about a girl named Mariam. This child is lost. She wants help from the player in returning to her home. During the return, Mariam asks the player many questions. It is one of the games that initially attract players to live in the atmosphere of a story while he is a hero with the heroine of the game. Then, it leads to terror, anxiety, isolation, and a reduction in sleep hours, as well as incitement to aggression against the other and suicide.

- The researcher reached some results through the opinion polls that she conducted before and during the field part of the research, namely;

$>\quad$ There is also (the game of fairies), this game targets the age group who are in the second to fourth grade of primary school. Its content is similar to the popular girls' dress-up game, but here is Fairy dress-up. They are also stages. Throughout these stages, children are dazzled by the characters of those fairies, which there is no permanent bodily harm. Upon reaching the 30th and last level, they say to the child: (If you want to be like fairies, and be in the game with us. Enter the kitchen at night when everyone in the house is sleeping. Close the door, open the gas, and sleep in the kitchen. After two hours, you will wake up and be A fairy with us in the game). Thus, the child would have committed suicide.

Some battle games have appeared, which are considered less piracy for their players, as it does not order them to kill anyone. The most famous of them is PUBG, which many countries have warned against due to its aggressive impact on social relations.

\section{FIFTH: RESEARCH RECOMMENDATIONS}

\section{Recommendations for Players}

$\sqrt{ } \quad$ A person can control another, to the extent that this other person allows this person to control him. Do not allow a game administrator to control you.

$\sqrt{ } \quad$ Organizing personal time; as specify times to work, and other times to play. $\checkmark \quad$ Communication with family and friends, and not to be isolated in the world of electronic games.

$\sqrt{ } \quad$ Attempting to engage in beneficial activities such as reading, playing sports, and group games.

$\sqrt{ } \quad$ Join social clubs, youth centers, and civil associations.

$\sqrt{ } \quad$ Replace violent games with purposeful ones.

\section{Recommendations for Family}

$\checkmark \quad$ Never underestimate children's exposure to the technological waves that come to them throughout the day. Many parents relieve themselves from their children and leave them in front of their mobiles. But, the family must know that it is the primary defender responsible for dealing with risks.

$\checkmark \quad$ Not being assured of leaving mobile phones to children who cannot write because there is now a feature to search for games by voice instead of writing.

$\sqrt{ } \quad$ The attempt of the father and mother to contain their children and create the language of dialogue, even in the presence of severe family disintegration. Lack of concern for one of the children and neglect of others. Avoid dealing with violence and cruelty.

$\sqrt{ } \quad$ Discovering and developing children's talents to invest their time in it, and motivate them upon academic success.

$\checkmark \quad$ Encouraging children to playgroup games that develop intelligence and instill a spirit of cooperation, such as tennis balls.

$\sqrt{ } \quad$ Take advantage of public and natural places for entertainment, according to children's preferences.

$\checkmark \quad$ Attempt to integrate children with the family; By assigning them tasks that they do that benefit the family, and sharing their opinions in decisions about the home.

$\sqrt{ } \quad$ Building children's immunity by developing their mental and social skills, to keep them away from dangerous games.

$\checkmark \quad$ Indirect follow-up of children's electronic life on the Internet, and their participation in their favorite games. 
$\sqrt{ } \quad$ Quick attention to psychological treatment when any symptoms of aggression appear on the son.

\section{Recommendations for Society}

$\sqrt{ }$ Holding educational seminars to raise awareness of the danger of modern electronic games. In addition to showing the cases that have been damaged by these games around the world, so that individuals are aware of their severity.

$\sqrt{ } \quad$ Activate (Cybersecurity): It is a term that refers to a wide range of information security issues ( $\mathrm{Al}$ Amro 2020). Thus, any country has the right to set laws and regulations to activate monitoring of online game sites. Blocking the dangerous ones, and punishing those who try to harm members of society.

$\sqrt{ } \quad$ Making new useful electronic games, as most of the time, something can only be fought with something other in the same field.

$\sqrt{ } \quad$ Work to make the curriculum enjoyable and appropriate for the mentality of the new generation. Also, every piece of information can be converted into an electronic game, to facilitate teaching it to children.

\section{REFERENCES}

Arab Naz and others: 2015, Media, Violence and the Culture of Victimization: A Sociological Analysis of the Socio-cultural and Psychological Impacts of Media on Youth, Pakistan Journal of Criminology _ Volume 7, pp. 73: $84 . \quad$ Available - at: https://www.researchgate.net/profile/Dr_Syeda Mahnaz Hassan/publ ication/283068251_Problems_Faced_by_Women_in_Police_Stations _Need_for_Police_Reforms_in_Pakistan/links/56286baf08ae22b1702 da25a/Problems-Faced-by-Women-in-Police-Stations-Need-for-

Police-Reforms-in-Pakistan.pdf\#page $=80$ (accessed on 19/10/2020).

Craig A. Anderson and others: 2008, Longitudinal Effects of Violent Video Games on Aggression in Japan and the United States, Pediatrics Official Journal of the American Academy of Pediatrics - Illinois United State. Available at: https://pediatrics.aappublications.org/content/122/5/e1067 (accessed on $1 / 10 / 2020)$.

https://doi.org/10.1542/peds.2008-1425

David B. Clarke: 2003, The Consumer Society and the Postmodern City, Routledge - London and New York, P. 16. Available at: https://books.google.com.eg/books?hl=en\&lr=\&id=JMI6V4owg3gC\&oi $=$ fnd \&pg $=$ PP $11 \& d q=$ The + principles + of + post modern+social\&ots=uqF82pGWE_\&sig=_kOjG3zJhki8LDrJvEO09aZPWY\&redir_esc=y\#v=onepage\&q=The $\% 20$ pri nciples $\% 20$ of\%20post-modern\%20social\&f=false (accessed on $1 / 10 /$ 2020).
Faten Sharif: 2006, Family and Kinship - Studies in Social Anthropology, Dar Al-Wafaa for the World of Printing and Publishing - Alexandria, p. 161.

Mehmet Emin Erendor, Mehmet Fatih Oztarsu: 2020, Contemporary issues in international relations, Cambridge scholars publishing, p. 290, 291. Available

https://books.google.com.eg/books?hl=en\&lr=\&id=RPXVDwAAQBAJ \&oi=fnd\&pg=PA290\&dq=Post-Modernism+social+theory\&ots=c2WbxWREs\&sig=Peb84Fs6R53IrzT915MU334voPA\&redir_esc=y\#v =onepage\&q=Post-Modernism\%20social\%20theory\&f=false (accessed on 27/9/2020).

Said Abd El-Razzak, Sharara Hayat: 2018, Electronic Games and Children "Reading in the Pros and Cons," Journal of Sociology for Social Studies and Research - Algeria, p. 220. Available at: http://ebiblio.univ-mosta.dz/handle/123456789/8113 (Accessed on 29/10/2020).

Saikat Chakraborty: 2019, Youth Engulfing Blue Whale: Monomania or Social Construct?, International Conference on Recent Trends in Humanities, Education, Arts, Culture, Languages, Literature, Philosophy, Religion, Gender and Management Studies (HEALM), pp. 12: 14 Available at: https://www.krishisanskriti.org/vol_image/03Jun201911061506\%20\% $20 \% 20 \% 20$ Saikat $\% 20$ Chakraborty $\% 20 \% 20 \% 20 \% 20 \% 2012-14$.pdf (accessed on 5/ 10/ 2020).

Salah Abdullah Mohammed Hassan: 2020, The University's Role in Confronting the Phenomenon of Intellectual Terrorism among its Students - Field Study on Assiut University, The Academic Journal of the Faculty of Education - Volume 36 - Number 3 - Assiut University, p. $44 . \quad$ Available at: https://mfes.journals.ekb.eg/article_99383_ac9e6c3595b8f8dbb3505d c94da38d41.pdf (Accessed on 14/11/2020).

Samira A. Kandil and others: 2016, factors related to disintegration of family relations and their relationship with psychological adjustment and feeling of loneliness among youth, Journal of agricultural economics and social sciences Mansoura University - Vol.7, pp. 23: 30 Available at: $\overline{\mathrm{h}}$ ttps://jaess.journals.ekb.eg/article_37237.html (accessed on $27 / 10 / 2020$ ). https://doi.org/10.21608/jaess.2016.37237

Shirin Ibrahim Mohammed: 2016, The role of the web in the disintegration of family relations field study in the city of Sulaymaniyah, Journal of AlFrahedis Arts _ Volume 8 _ Issue 24 _ Tikrit University _ Iraq, p. 451 Available at: https://www. iasj.net/iasj/download/f9b41̄ b06e91a24b0 (accessed on 29/ 10/2020).

Steven Seidman: 1998, The Postmodern turn _ new perspectives on social theory, Cambridge university press, p. 10. Available at: https://books.google.com.eg/books?hl=en\&lr=\&id=bcfEKowDrwC\&oi=fnd\&pg=PA1\&dq=Postmodernism+Theory+sociology\&ot $\mathrm{s}=\mathrm{mjQ} 2 i p w-x O \&$ sig $=$ Zo3IPG-

Y6QVy0N1KJ1ScyGYhV5c\&redir_esc $=y \# v=$ onepage\&q=Postmoderni sm\%20Theory\%20sociology\&f=false (accessed on 29/9/2020).

Sulaiman Al Amro: 2020, How safe is governmental infrastructure: A Cyber Extortion and Increasing Ransomware Attacks Perspective International Journal of Computer Science and Information Security (IJCSIS), $\quad$ p. $\quad 80 . \quad$ Available at: https://d1wqtxts1xzle7.cloudfront.net/63787582/09_Paper_01062024 IJCSIS_Camera_Ready_pp79-8220200630-84878-

13v9h94.pdf?1593523853=\&response-content-

disposition=inline \%3B+filename\%3DHow_safe_is_governmental_infr astructure.pdf\&Expires $=1601685661 \&$ Signature=EGDKg4UowFLqYc FYHQYfN2Wm6VCw23mqFcKCL 15eJpnFsudugdvKIGJxNqWvapA4pc 5SK6RrQ9niAo9Nr Qandl7EmWt08NeX7T6alkEeH6Aa7 c85KoTtym7qujCrAHntQ2Y-

2YS7tkbKstuxskkLFIRTEfOMobep19JxBygJa9u68KU5kDMoN6gmF72 jAFxTScr5pb0wPZW1XIIRQOCvc8JPv-

nSnrohRw71Gejs7juv4jHG8RD5S8IMdqeJFsXd-9m8dPJtxuuxEeR1c-7TY6t8QsSh3BEAWd7ZvjvuborANoU1M KFFmtXolCCb3Osz6zCSOyERRhJHsQg \&Key-PairId=APKAJLOHF5GGSLRBV4ZA (accessed on 3/ 10/ 2020).

(C) 2021 Heba Atef El-Sayed Mahmoud Awad; Licensee Lifescience Global.

This is an open access article licensed under the terms of the Creative Commons Attribution License (http://creativecommons.org/licenses/by/4.0/) which permits unrestricted use, distribution and reproduction in any medium, provided the work is properly cited. 